\title{
LITERATURA, CRÍTICA IMANENTE E O PROBLEMA DO PONTO DE VISTA ${ }^{1}$
}

\author{
Neil Larsen \\ nalarsen@ucdavis.edu
}

O que segue é um rascunho rápido e condensado da argumentação central de um work-in-progress maior, que tem agora o provável título grandioso de "Princípios de Crítica Imanente". Meu objetivo mais imediatamente prático em escrever tal trabalho é de veicular para o público, especialmente aos estudantes, o perfil de um método proposto para a teoria crítica nas humanidades e os "estudos culturais" em geral e, mais particularmente, em relação à literatura como um objeto críticoteórico possível. O pensamento preliminar por trás desse projeto é o resultado de aproximadamente dez anos de ensino de teoria crítica em salas de aula tanto de graduação quanto de pós. Durante esse período, eu passei a desconfiar e finalmente rejeitar a pedagogia já padronizada, eclética, refletida na maioria dos guias e introduções da "teoria" nos quais as várias escolas de "teoria" convencionalmente identificadas - do feminismo ao pós-estruturalismo, ao marxismo e à psicanálise - são explicados um a um. É claro que alunos, especialmente aqueles procurando um trabalho na academia, precisam saber essas coisas, mas o resultado intelectual de apresentar a teoria crítica ou "literária" como,

1. No original, "standpoint", que deve ser compreendido literalmente como "ponto de onde se vê" e não relacionado à tradição teórica sobre foco narrativo [N. do T.]. 
digamos, tudo contido entre as capas da Norton Anthology of Theory and Criticism é, o que mais que isso seja, antitética ao próprio conceito de teoria em si, que precisa insistir, como um postulado metodológico, em sua própria universalidade e exclusividade em relação a seu objeto. Ensinar as várias escolas "criticamente" - diga-se, do ponto de vista do marxismo ou feminismo, não importando como esses pontos de vista devam ser definidos - pode, em princípio, evitar essa armadilha e isso tem, de fato, sido minha própria prática na sala de aula de "teoria". Porém, para praticar até esse método crítico e metateórico de uma forma consistente e rigorosa ainda será necessário um avanço que se soma não só a uma teoria crítica da "teoria" em si (algo que eu também venho trabalhando na forma de um estudo de referência a "Princípios de Crítica Imanente"), mas também que se possa explicar, do ponto de vista pessoal de cada um, o procedimento do qual resultados intelectuais válidos serão obtidos. É, certamente, um critério básico da teoria que sua verdade seja reprodutível por qualquer um que assuma seu ponto de vista e pense através e a partir de seus axiomas e categorias - que é o mesmo que dizer, reprodutível por qualquer pessoa que deva aprendê-la. Nesse caso, então, este é um critério sob o qual aquilo que passa por teoria nas humanidades falha, abjetamente, em cumprir. Teoria crítica, se ela deve ser consistente com seus próprios princípios, tem que se comportar diferentemente.

Começo essa exposição um pouco estranhamente, apresentando dois problemas, ou pontos de partida, aparentemente díspares. O primeiro é explicitamente teórico e provavelmente tem uma forma abstrata "ruim" nesse momento, mas enquadra a totalidade do que estarei discutindo aqui: no que consistem a teoria e prática da crítica imanente quando relacionadas especificamente a objetos culturais e, em particular, literários? Quais são seus princípios metodológicos básicos em relação a tais objetos? Tomo como dados, e sem precisar necessariamente discutir aqui, os princípios da crítica imanente no caso da teoria crítica social, inaugurados e ainda resumidos por $O$ Capital, de Marx, em relação a seu objeto: a forma social reificada da modernidade capitalista. A crítica imanente nesta forma, para citar a formulação lúcida e sucinta de Moishe Postone em Time, Labor, and Social Domination,

não julga criticamente o que pertence a uma posição conceitual externa a seu objeto - por exemplo, um "deveria" transcendente. Ao invés, ela deve conseguir localizar esse "deveria” como uma dimensão de seu próprio contexto, uma possibilidade imanente à sociedade existente. Uma crítica assim também deve ser imanente no sentido de conseguir apreender a si própria reflexivamente e embasar a possibilidade de sua própria existência 
na natureza de seu contexto social. Isto é, para ser internamente consistente, precisa conseguir embasar seu próprio ponto de vista nas categorias sociais com as quais apreende seu objeto, e não simplesmente postular e assumir aquele ponto de vista. $\mathrm{O}$ existente, em outras palavras, deve ser apreendido em seus próprios termos de forma que englobe a possibilidade de sua própria crítica: a crítica deve conseguir mostrar que a natureza de seu contexto social é tal que este contexto gera a possibilidade de uma instância crítica sobre si mesmo. Segue-se, então, que uma crítica social deve mostrar que seu objeto, a totalidade social de que faz parte, não é uma totalidade unitária (Postone, 1996, pp. 87-88).

Postone continua a argumentar que o desenvolvimento completo da crítica imanente marxista em $O$ Capital, posto que resulta na inclusão de seu próprio ponto de vista em seu objeto histórico, também implica na especificidade histórica da teoria em si:

Isso implica na necessidade de um novo tipo de crítica, autorreflexiva. Seu ponto de vista não pode ser posicionado trans-historicamente ou transcendentemente. Em uma estrutura conceitual assim, nenhuma teoria - incluindo a de Marx - tem uma validade trans-histórica absoluta. A impossibilidade de um ponto de vista teórico extrínseco ou privilegiado [...] não deve ser transgredida implicitamente pela forma da teoria em si própria [...] O Capital, em outras palavras, é uma tentativa de construir uma argumentação que não tem uma forma lógica independente do objeto a ser investigado, quando esse objeto é o contexto da própria argumentação (Postone, 1996, pp. 140-141).

É imediatamente evidente a partir do discutido acima que a questão do que constitui uma crítica cultural ou literária imanente de pronto e necessariamente implica em outras, anteriores e mais fundamentais: qual, por exemplo, é a relação precisa e determinada - se ela existe entre a "literatura" como objeto e o objeto socialmente e historicamente específico da teoria crítica como teoria social (ou, como Postone coloca, da crítica social imanente)? Pode a "literatura" em si ser compreendida, de qualquer forma determinada ou conceitualmente precisa, como uma "totalidade não-unitária"? Quais, então, seriam suas contradições internas? E - talvez resumindo todas as questões anteriores - no que constituiria o ponto de vista da crítica imanente no caso de um objeto cultural ou literário?²

Estas não são perguntas novas ou desconhecidas. A teoria crítica e a crítica literária marxista em geral abordaram-nas de uma forma ou outra

2. Desconsidero, aqui, por questões ilustrativas, o problema da relação exata da "literatura", como forma e categoria, com a "cultura", e as trato como isomórficas. 
desde seu início. Porém, a extensão e a riqueza das respostas contrastam com o que foi simultaneamente um déficit de clareza metodológica, rigor, ou consenso no tocante aos princípios e categorias fundamentais de uma crítica imanente da literatura e sua ordem de determinação precisa e dialética. Muito da mais lida teoria e crítica literária marxista, supostamente dialética, particularmente em suas variantes francesa e anglo-americana, traz pouca, se alguma, relação com os princípios gerais da crítica imanente marxista como delineada acima por Postone, e os reduz, na melhor das hipóteses, ao nível de uma crítica-ideológica na qual a literatura é lida como mais um efeito superestrutural. Alguém ficaria pouco confortável para achar em Raymond Williams, Pierre Macherey, ou Terry Eagleton, digamos, algo remotamente semelhante a uma crítica teórica "empreendida de um ponto de vista que é imanente, em vez de exterior a seu objeto de investigação" (Postone, 1996, p.21). As exceções mais significativas, aqui, situadas mais próximas ao núcleo cultural da Europa Central do marxismo hegeliano e da teoria crítica propriamente, são Lukács e Adorno, que fizeram esforços sistemáticos para integrar realidade e crítica estética nos princípios dialéticos gerais da crítica imanente. Contudo, ésintomático do mesmo déficit metodológico, mesmo em um estágio superior, que obras como O Romance Histórico e Teoria Estética encontrem-se em uma oposição diametral - e dialeticamente não mediada - entre si. Lukács, em particular, qua marxismo do início do século XX, e mais metodológicamente ortodoxo, deu as respostas mais inequívocas para a questão do ponto de vista - a do proletariado como classe revolucionária. Porém, essa é uma resposta que agora quedou vitimada pelos desenvolvimentos históricos, cuja própria imanência a teoria estética lukácsiana não detectou, talvez nem conseguisse detectar. Isso não se deu, em minha visão, porque as alegações que Lukács abrigou em História e Consciência de Classe em nome do "ponto de vista do proletariado" fossem excessivamente messiânicas ou "idealistas", mas porque, como a crise contemporânea do capitalismo indiscutivelmente deixa claro, nenhuma classe, mas somente a sociedade sem classes em si, na verdade a própria possibilidade do social em face ao extermínio social do capital, poderia redimi-los. A teoria estética e crítica de Adorno pareceu sair-se melhor na conjuntura tardia moderna, e é, inquestionavelmente, a Adorno que alguém deve voltar-se primeiramente e sobretudo procurar os princípios de uma crítica imanente literária ou estética. Porém, dado o ceticismo de Adorno acerca do método em si - algo espelhado em reflexões frequentemente crípticas, paradoxais e "metodicamente sem método" na imanência metodológica da crítica a ser encontrada até nos mais explícitos de seus escritos sobre o assunto - a busca de um ponto de 
vista verdadeiramente dialético provará ser árdua e também altamente problemática em si (v. ADORNO, 1983; 1991; 1976). Como argumentei em outro lugar, Adorno pressentiu mais perspicazmente que qualquer outro pensador da época ou desde então a verdade imanentemente negativa da dialética da arte e da cultura justapostas ao trabalho concreto ou ao fenômeno cultural 3 . Porém, ele enquadrou sua própria perspicácia ensaística e aforística nos termos de uma teoria política e social monolítica, efetivamente subhistoricizada (o que Postone nomeou de "pessimismo crítico" da Escola de Frankfurt) que por sua vez forçou sua teoria crítica, precisamente em seus momentos mais poderosos e ricos, a uma forma que tendia à irreprodutibilidade metodológica ( $v$. POSTONE, 1996, pp. 84-120).

Antes de confrontar o problema do ponto de vista imanentemente crítico qua "literatura" no plano diretamente categórico, contudo, e suspender aqui o que é, a longo prazo, provavelmente a estratégia mais produtiva e frutífera, de espírito mais imanente em si, de perseguir essa questão através de um estudo mais cerrado e uma crítica à crítica imanente de Adorno em si (talvez com uma série de olhares laterais a Lukács), proponho chegar a essa questão, por assim dizer, de baixo, ao situá-la em seu contexto pedagógico e mais imediatamente intelectualfenomenológico. Isso, então, introduz o segundo problema, ou ponto de partida, que desenvolverei mais longamente a seguir, retornando por essa via à forma mais abstratamente teórica da questão como inicialmente formulada acima.

Qualquer um que recebeu a incumbência de ensinar "teoria" em relação à literatura - ou de ensinar literatura "teoricamente" - e que tentou fazer isso de uma forma sistemática e metódica vai, cedo ou tarde, achar-se em um dilema familiar: como satisfazer às expectativas de que a "teoria” em questão seja "aplicada" à literatura, esta última quase invariavelmente incorporada em uma obra ou "texto" particular. Digamos - e aqui eu delineio minha própria experiência recente de sala de aula em tentar ensinar teoria crítica para alunos de graduação de Literatura Comparada - que a "teoria" seja a psicanálise, especialmente o ensaio de Freud sobre o estranho, e o texto seja um espécime seminal dos livrostexto de "teoria", Amada de Toni Morrison. Especialmente se o que passa na literatura institucional por leitura "teórica" de tais textos funciona como modelo, parece-me que a "aplicação" dos conceitos psicanalíticos no objeto deve seguir. Porém, como, exatamente? Depois da seleção

3. "The Idiom of Crisis: On the Historical Immanence of Language in Adorno" (2010). 
da "teoria" e do texto - e deixando de lado, aqui, a questão de o quê, metodologicamente, justifica algo como essa cópula - qual é o próximo passo de tal análise ou crítica "teórica"? Se a psicanálise é tomada em seu nível mais geral e categórico como, digamos, a teoria do inconsciente, o que, então, faz esse último aplicável a Amada? Especulações acerca do inconsciente de Morrison? Acerca do inconsciente das personagens principais do romance? Essas são geralmente as "aplicações" primeiras, mais baseadas no senso-comum, favorecidas pelos alunos, mesmo que as falácias aqui sejam óbvias para o "teórico" literário mais experiente. Porém, se isso não é o significado de "aplicar" a teoria nesse caso, então o que é? Uma solução mais prática e provável seja talvez restringir o alcance de "aplicação" e, digamos, analisar Amada por exemplos dos afetos que Freud descreve como estranhos [unheimlich], especialmente quando a própria interpretação freudiana de "O homem de areia", escrito por Hoffmann, pode ser recomendada aos alunos como modelo. Porém, suponha-se então que nenhum exemplo claro do estranho possa ser detectado em Amada. E então? Seria a teoria do estranho a teoria errada - significando que outra precisa ser encontrada? O interesse de Freud no estranho em "O Homem de Areia" não é, finalmente, literário, mas terapêutico, ou, mais geralmente, psicológico, e o texto de Hoffmann serve a ele como uma rica fonte desse afeto - e talvez, dessa forma, um ponto estratégico melhor sobre o fenômeno geral da repressão e seus sintomas neuróticos - do que é oferecido tipicamente pela "psicopatologia da vida cotidiana". Porém, se o que é buscado na "aplicação" da teoria ao texto é algo na ordem de uma "crítica", então como, por sua vez, a detecção deste ou daquele afeto ou qualidade sintomática em Amada promove esse fim?

Aqui e ali, algum insight genuinamente interpretativo pode resultar de tais colisões repetidas essencialmente a esmo entre "texto" e "teoria". Leitores de Amada armados com o ensaio de Freud podem ser atingidos, por exemplo, por quão indubitável é uma ausência relativa de estranho no romance, dado que se trata de uma história centrada no lócus paradigmático de estranheza, a casa mal-assombrada. Em nenhum lugar está escrito, é claro, que uma história de fantasmas deve ser amedrontadora ou estranha, mas o fato de que Amada, um romance que tematiza autoconscientemente o retorno da violência da escravidão reprimida ou internalizada, prefere - em uma obediência evidente às formulas standardizadas do estilo do "realismo mágico" de García Márquez - um fantasma estilizado, domesticado e quase etnográfico a um assustador pode sugerir a seu aspirante a psicanalista que o lugar genuíno da repressão no inconsciente do romance jaz em seu tratamento 
familiar [heimlich] do material intrinsecamente estranho. Porém, mesmo que essa linha de análise consiga conectar elementos de outra forma díspares e problemáticos no romance, ela permanece essencialmente descritiva. Nada aqui, "teórico" ou "textual", embasa - isto é, torna necessário - o movimento da interpretação à crítica. Pode-se discutir plausivelmente que a "não estranheza" de Amada (admitindo que esse resultado interpretativo é convincente em face às objeções de leitores que afirmam que são amedrontados por Amada) é prova, digamos, de sua capacidade de mestria simbólica - de sublimar - a violência reprimida da escravidão como prova do deslocamento neurótico da própria violência que ele indica trazer à consciência. E ambas essas leituras crítico-teóricas pretendidas de Amada pressupõem como "crítico" o que corresponde ao julgamento de valor psicanalítico e terapêutico, de acordo com o qual a liberação dos impulsos ou experiências reprimidas conta como um objetivo desejável. Seria perverso, qua psicanálise, contestar isso, mas em lugar algum está escrito, também, que romances são análogos à psicoterapia.

E assim por diante. Da mesma forma que "texto" e "teoria", mesmo esclarecendo sua articulação subsequente e acidental, aparentam colidir em um espaço irracional de pura imanência e indeterminação, então, também, os objetivos cognitivos e críticos da teoria per se aparentam, inevitavelmente, existir independentemente, se não em oposição absoluta aos outros. No entanto, procuram-se em vão nos cânones e na copiosa literatura pedagógica por vislumbres de suspeita que algo está em falta na casa da "teoria".

Porém, alguém educado no pensamento dialético deve reconhecer nessa patologia intelectual - o que me referirei a seguir como "falácia da aplicação" - os sintomas de uma reificação. "Teoria” e "texto", "interpretação" e "crítica", não são meramente acidentes mútuos, mas são estruturados como antinomias. A partir do momento em que seu objeto torna-se um "texto", qualquer teoria "aplicada" a ele - não importando que seja a psicanálise, narratologia estruturalista, ou mesmo o marxismo, não importando sua riqueza imanente e mediação conceitual - é reduzida a um mero fetiche intelectual, uma espécie de tautologia abstrata. O mesmo vale, inversamente, para os "textos": enquanto "lidos" por uma teoria compreendida, a priori, como externa a sua própria mediação objetiva, tornam-se cifras rígidas, tão sem sentido, finalmente, em relação à interpretação quanto são significantes em seus próprios contextos imanentes.

De uma ou outra forma, incluindo a artimanha preferida atualmente e igualmente pseudoteórica que julga em evitá-la ao substituir um 
objeto literário por um "cultural”, a "falácia da aplicação" imbui e, de certa forma, define a disciplina humanística da "teoria", quer literária, cultural, ou outra. Esse fato pode, certamente, significar quase nada para o problema teórico do ponto de vista imanente com o qual começamos. As entidades disciplinares conhecidas por "teoria" e "literatura" nunca devem, ao custo de uma autotrivialização crítica automática, ser confundidas em seu conteúdo genuíno enquanto conceitos para a teoria crítica extra muros. No entanto, se submetida a uma segunda reflexão especificamente ao longo de sua estrutura aparentemente antinômica isto é, até aqui, imanentemente - a "falácia da aplicação" pode ser forçada a apontar para além de si mesma. Pode-se, por exemplo, colocar uma questão (e essa estratégia eu sigo com meus alunos) de por que se assume que a "teoria" nesse contexto deva ser "aplicada" em primeiro lugar? Em que tipos de objetos é a teoria, como compreendida mais geralmente e convencionalmente fora do contexto crítico-literário, "aplicada"? A resposta - que a teoria no caso, digamos, de uma teoria do aquecimento global é aplicada a dados, a fatos - incita a próxima pergunta: é Amada (ou a própria literatura) um dado empírico da forma que, por exemplo, o aumento da temperatura dos oceanos? A resposta para isso pode não ser óbvia, na medida em que o objeto convencionalmente designado por Amada aqui aparenta ter propriedades empíricas, como a combinação precisa de palavras em suas páginas, ou o fato de que Morrison o escreveu, em um tempo e espaço específicos, etc. Porém, são esses os tipos de propriedades empíricas de Amada aos quais estamos tentando "aplicar" a teoria do estranho de Freud?

Aqui, o auxílio do próprio Freud pode novamente ser invocado. Em que tipos de objetos - se deixarmos de lado aqui o tipo literário no caso de "O Estranho" - é a teoria psicanalítica aplicada? A resposta, neste caso, é múltipla e complexa - englobando o sintoma neurótico, as parapráxis, o próprio inconsciente - mas, incluída nele estaria, incontroversamente simplesmente um afeto, posto que é, em sua base, a categoria psicológica à qual o estranho pertence. "O Homem de Areia" interessa a Freud aqui como um objeto para a psicanálise somente na medida em que produz uma sensação especialmente vívida do estranho em seus leitores - isto é, pelas propriedades afetivas da própria narrativa. Não é, afinal de contas, às propriedades afetivas de Amada, sejam quais forem - ou, melhor, à forma do romance como um objeto que gera ou extrai afetos - que a teoria psicanalítica do estranho é corretamente "aplicada"?

Essa argumentação pode parecer excessivamente elementar e ingênua para os adeptos da "teoria", mas de fato ela já nos fornece uma estrutura lógica para sair da "falácia da aplicação" reificante - uma 
falácia à qual nenhuma forma de teoria não dialética, não importa o quão sofisticada, deixa de sucumbir, cedo ou tarde. Pois, mesmo que afetos como o estranho possam ser de fato tratados como dados empíricos - algo que o próprio Freud como, de certa maneira, seu observador científico os considera - sua forma como objetos quando os "observamos" em "O Homem de Areia" ou Amada não é a mesma de, digamos, um aumento da temperatura dos oceanos. Como leitores desses "textos", não podemos observar tais objetos "afetivos" sem observar sua presença (ou, para todo caso, sua ausência) em nós mesmos. Afetos como o estranho, em outras palavras, não são de maneira alguma objetos verdadeiramente empíricos, mas objetos na forma simultaneamente subjetiva, ou - o uso hegeliano agora é praticamente inevitável - "sujeitos/objetos". Isso se torna mais claro, pelo menos para meus alunos, se então consideramos o tipo de objeto narrativo pré- ou quase-literário por cuja análise Freud é mais celebrado: os sonhos. Todos se perguntam o significado de seus próprios sonhos, isto é, até certo ponto, tratam-nos como objetos teóricos. Porém, ao "aplicar", digamos, os métodos analíticos expostos em A Interpretação dos Sonhos em nossos próprios sonhos, "aplicamos" tais métodos reflexivamente a nós próprios. Não somos "nós" nossos próprios sonhos - e, no entanto, ao mesmo tempo, também não nossos próprios sonhos, na medida em que os objetivamos e os tratamos independentemente de nossa imanência subjetiva? Não é o sujeito que sonha - tanto como sujeito individual quanto coletivo - contínuo, não obstante inconscientemente, com o sujeito "aplicando" a teoria, ou melhor, com a teoria em si como "sujeito"? Como "sujeito/objeto", o sonho - e não menos a representação literária que são "O Homem de Areia" e Amada - difere de um dado empírico como o aumento das temperaturas dos oceanos não só qua fato ou objeto de "aplicação" teórica, mas qua sua própria forma de objetividade. A falácia crua, relativista (uma gêmea neocartesiana à falácia da aplicação) deve em si ser repelida nesse momento? A dimensão "subjetiva" de, digamos, objetos afetivos como sensações do estranho, seja em sonhos, sintomas neuróticos ou narrativas literárias, não torna sua teorização menos "objetiva”. Pensar assim é acreditar que o sujeito que teoriza é finalmente descontínuo com o sujeito que sonha, que sente, que lê, ou, de fato, que escreve. Não há sujeito teorizante externo às formas afetivas e representacionais que mediam - ou de fato são também este sujeito. Para ouvidos pré-dialéticos, a expressão ainda soará paradoxal ou esotérica neste ponto da exposição pedagógica, mas sua lógica, como a do "sujeito/objeto" tornou-se inevitável: objetos teóricos na forma de "sujeito/objetos" são, eles mesmos, como resultado de sua formação, não menos sujeitos de sua própria "teorização". Sua 
"Teoria” não vem a eles, em qualquer sentido absoluto ou final, de fora de seus próprios seres como objetos - assim, não é "aplicada" a eles de forma alguma de acordo com o sentido padrão e empírico de "teoria". A teorização de objetos cuja forma de objetividade é comum aos afetos, sonhos, narrativas, etc., é, do ponto de vista dessa própria forma, ao mesmo tempo, sua autoteorização. A teoria, então, não é “aplicada”, mas é imanente a tais objetos. Aqui, temos o primeiro e mais básico princípio metodológico da crítica imanente em relação a objetos literários, não importando o quão contraintuitivo e paradoxal isso ainda possa parecer para ambas as críticas convencionalmente beletrísticas ou teóricas.

Nisso, é verdade, a crítica imanente em sua relação metodológica com a literatura não seria ainda distinguível do método da crítica social imanente exemplificada em $O$ Capital e exposta por Postone - ou, em todo caso, da relação imanente entre conhecimento e seu objeto como argumentado na Lógica de Hegel. A certeza abstrata de que um "texto" como Amada é um objeto imanentemente subjetivo e não-empírico, e, portanto, já presente em qualquer consciência teórica de si como objeto, ainda não nos dá uma ideia clara do que sua crítica significaria, ou como empreendê-la. Assim estamos, aparentemente, longe de descobrir o que constitui - se há algo - o ponto de vista preciso e determinado da crítica imanente como crítica "literária". Contudo, o mero fato de que se a derivação prática e, por assim dizer, negativamente fenomenológica esboçada acima for válida - a superfície de um objeto como Amada não ofereça nada imediato para conectá-la com a "teoria" em sua forma não-dialética, cartesiana-empírica, já nos conta mais que isso. Porque o objeto literário, em contraste com o mais geral e abstratamente social objeto da teoria, sugere, se o faz, uma impenetrabilidade quase irracional à "ciência" positiva e empírica. O abstratamente social, aqui, parece mais vulnerável à reificação que o objeto literário - de onde o fato que a "sociologia da literatura", apesar de suficientemente real em um sentido trivial e disciplinário, não é mais "aplicável" como teoria para o objeto literário em si que, digamos, uma mera contagem de palavras. $\mathrm{O}$ objeto literário como "sujeito/objeto" funde-se, no fim, com o social como uma categoria completamente dialética, mas a distância separando-o de um método dialético, imanentemente crítico aparente, mesmo que somente negativamente e "irracionalmente", é tanto mais curta e, no entanto, mais oculta e abissal. A reificação da "literatura", ao contrário da reificação da sociedade, leva direta e espontaneamente para uma terra de ninguém de auto-paródia e paralisia teórica e metodológica. Como na derivação "pedagógica" acima, a teoria, na realidade, tropeça em sua própria relação imanente com o objeto literário porque todos os outros modos de acesso 
foram-lhe negados.

Porém, para levar esse pensamento adiante, precisamos primeiro especificar mais precisa e conceitualmente a realidade formal ou categórica do objeto "literário" em relação à teoria crítica. Denominamos a forma da objetividade à qual a "literatura", juntamente com o afeto, o sonho, a narrativa, etc., pertence - pelo menos como um contexto imanente da psicanálise - como uma de "sujeito/objeto". Porém, essa distinção, também - apesar de somente por seus meios a "literatura" entrar no domínio geral do pensamento dialético - falha em isolar a categoria concreta através da qual a forma "literária" do "sujeito/objeto" media e é mediada por sua relação com a totalidade social.

Qual é essa categoria? Um retorno a nosso experimento de pensamento pedagógico pode novamente ajudar a pegar o fio da meada. A tentativa mal conduzida de "aplicar" a teoria psicanalítica em Amada forçou-nos a uma antinomia "teórica" da qual se tornou possível concluir, via negocionis e com o auxílio de uma lição de interpretação provida por Freud em "O Estranho", que o objeto literário em si precisa possuir qualidades "subjetivais" - qualidades pelas quais assemelhou-se aos objetos mais convencionais da psicanálise. Porém, essa semelhança em si, a afinidade óbvia do objeto literário com sonhos e vários outros tipos de objetos psíquicos analisados por Freud, claramente revela mais que a mediação subjetiva de tais objetos. Porque o que determina essa, por assim dizer, intuição pré-teórica de semelhança repousa não só no que é pressentido como a presença a priori do sujeito no objeto, mas em uma forma específica e concreta de sua mediação. Em ambos os objetos, o "literário" e, mais geralmente, o psicanalizável, um sujeito media a si próprio através de um objeto conscientemente, e esse meio objetivo deve, por sua vez, possuir as qualidades que tornam essa mediação consciente possível ${ }^{4}$.

A questão, então, ausente à "falácia da aplicação" - isto é, uma vez que a forma pseudoempírica do objeto literário foi descartada pela teoria crítica como ora não essencial, ora uma reificação em si - torna-se aquela desse meio objetivo em si. Isso só pode ser o que é comum a objetos "literários" como Amada e "O Homem de Areia" e outros "sujeitos/ objetos" afetivos como sonhos, sintomas, parapráxis, etc.: não "afeto" per se, posto que ele pode tomar uma forma puramente não-mediada e subjetiva, mas aquilo que o transmite ou reproduz aqui, nominalmente,

4. Compreendo a categoria freudiana do "inconsciente" aqui como contínua com o consciente. A "inconsciência das relações sociais expressadas no fetiche da mercadoria" carece - como veremos aqui - dessa propriedade de continuidade. 
a narrativa, o simbólico, a representação, etc. Em uma palavra: mimese.

"Mimese", para muitos de nós evocará, é claro, a tradição agora efetivamente defunta do aristotelianismo e as figuras escassamente menos respeitáveis de um Auerbach ou um Frye - os avatares de uma estética de imitação há muito considerada obsoleta no rastro do modernismo, a avant-garde e, finalmente, da "teoria" contemporânea em si, especialmente em sua "virada linguística". De fato, a mimese como uma categoria teórica desempenha um papel central, mesmo que de formas amplamente divergentes, na estética dialética de ambos Lukács e Adorno. Porém, colocando de lado mais uma vez quaisquer incursões no último terreno, e meramente argumentando em conformidade com o axioma dialético que categoriza o objeto "literário" como uma forma do "sujeito/objeto", a mimese pode ser identificada especulativamente aqui como aquela categoria já inferida da derivação pedagógica precedente: o processo em que um sujeito media a si mesmo através de um objeto, mas aqui como um processo acontecendo na e pela consciência (ou no e pelo inconsciente). Tudo que falta dessa categoria dialética aqui - por razões que logo ficarão aparentes - é o postulado de sua determinação essencial como uma unidade mediada de sujeito e objeto diretamente social, bem como consciente. A mimese agora nomeia, em outras palavras, a relação dialética entre sujeito e objeto como uma relação consciente e diretamente social.

Um objeto como um sonho, uma narrativa verbal, ou uma representação visual não seria, neste sentido, denominada "mimética" simplesmente porque um sujeito lança mão dela para "imitar" um objeto externo a si - a noção não-dialética, de senso comum, de mimese herdada da tradição clássica e reproduzida em críticos como Auerbach. Tais objetos são denominados "miméticos" aqui porque são os meios pelos quais um sujeito - ele próprio imediatamente social mesmo quando "privado" e portanto já presente em seu próprio objeto - continuamente reobjetiva a si próprio, e no qual um sujeito potencialmente reconhece a si mesmo.

Desse ponto de vista, a teoria clássica da mimese, especialmente como delineada na Poética, pode, apesar de formalmente não dialética, tornar-se singularmente elucidativa para a teoria e o método dialéticos. Considere-se, por exemplo, a estipulação de Aristóteles, no segundo capítulo da Poética, de que a tragédia toma como seu objeto essencial de imitação a ação humana, ou a "práxis". A Poética já considera isso, de maneiras que parecem antecipar a dualidade moderna, reificada e cartesiana do sujeito-objeto, como uma relação externa e instrumental do sujeito imitador (a ação selecionada para a representação trágica). 
Contudo, a separação entre sujeito mimético e objeto - uma separação já em curso na República de Platão, mas que este tenta reverter através da regulação e policiamento do estado - permanece relativa. O sujeito cuja ação é imitada e o sujeito imitando-a, enquanto aparentam ser para Aristóteles entidades separadas, são, contudo, redutíveis à mesma substância: essencialmente, o sujeito que é a sociedade em si, ou polis. A "práxis", nesse nível do "sujeito/objeto" social, compreendido por poeta, ação trágica e plateia, imita a si mesma - uma dialética cujos perigos políticos para o estado platônico foram, pelo liberalismo aristotélico, reduzidos a problemas de julgamento e bom gosto. O poema trágico, enquanto afirma sua própria autonomia relativa como um instrumento mimético, não pode, contudo, ser concebido externamente à sua imanência social - daí sua suscetibilidade à prescrição e a um tipo de etiqueta teórica. Ele permanece, em última instância, a imitação de um objeto, fora de cujo contexto imanente e essencialmente local, a própria imitação perderia todo o sentido ou propósito - um objeto, em outras palavras, que, ao nível da totalidade social, permanece, da mesma forma, sujeito. A Poética, como a teoria platônica que criticou e racionalizou, impele virtualmente ao limiar conceitual da reificação cartesianística, de uma teoria de representação puramente abstrata e instrumentalizada. Porém, ela não pode cruzar esse limite e, portanto, o elo mimético permanece, para ela, sendo texto instrumental quanto social.

Contudo, mesmo que a teoria clássica da mimese chegue perto de cair em seu encantamento, ela prefigura uma "práxis" que é "humana" (isto é, social), mas não consegue reconhecer a si própria como social, tornar-se, como práxis, um "sujeito" consciente. Isso não é outra coisa que a ação social das mercadorias teorizadas por Marx em O Capital, livro I, capítulo 1, na seção sobre o fetiche das mercadorias ${ }^{5}$. Como na expressão útil de Postone, uma "forma de mediação social", a "objetividade fantasma" da mercadoria, ou simplesmente de "valor", converte a ação da sociedade como um todo em algo puramente material e espontaneamente não acessível à consciência. Tomo a teoria do fetiche da mercadoria de Marx - fons et origo da teoria crítica moderna - para não precisar de mais

5. "O caráter misterioso da forma-da-mercadoria consiste, portanto, simplesmente no fato de que a mercadoria reflete as características sociais do próprio trabalho humano como características objetivas dos próprios produtos do trabalho, bem como as propriedades sócio-naturais dessas coisas. Assim, ele também reflete a relação social dos produtores à soma total do trabalho como uma relação social entre objetos, uma relação que existe em separado e externamente aos produtores.” MARX, K. Capital, vol. I. trad. Ben Fowkes. London: Penguin, 1990. pp. 164-65. 
explicações aqui. É suficiente a este momento observar que o objeto reificado qua forma da objetividade também conta como um "sujeito/ objeto", mas um que media a si mesmo "pelas costas" da forma-subjetiva à qual corresponde. Como formas mediadas de "sujeito-objeto", valor e mimese são opostos, na verdade, antitéticos um em relação ao outro. A sociedade reificada da modernidade capitalista falha, como sujeitos, em tornar-se consciente de si mesma na abstração de valores, um objeto que, por assim dizer, "reconhece" a si próprio somente em outros objetos similares. O valor, como incorporado à forma mercantilista do objeto, representa dessa maneira o objeto não mimético por excelência.

Com essa tese ainda, sem dúvida, altamente abstrata e especulativa - a contradição dialética entre valor e mimese como formas socialmente mediadoras do "sujeito/objeto" - chego ao sustentáculo da presente argumentação. Conduzir mesmo uma breve descrição do que são, em se confirmando, suas implicações completas excederia em muito os limites do que tento realizar aqui. Meu método para auferi-la, através de um in medias res pedagógico e uma reflexão oblíqua e provavelmente amadora sobre a teoria clássica da mimese, lança-se para além do que seriam claramente uma grande série de argumentações teóricas e clarificações necessárias. Uma das maiores concerne o conceito de mimese como uma categoria socialmente mediadora, algo que postulei aqui sem qualquer contexto adequado. Estou convencido de que a dimensão constitutiva mais profunda da mimese como uma forma social - uma dimensão sem a qual seus aspectos superficiais estéticos, etnográficos e psicológicos permanecem aprisionados em uma perspectiva descritiva, acrítica e empobrecida teoricamente - pode ser derivada rigorosamente da teoria crítica madura de Marx, e da elaboração posterior dela em um trabalho como o de Postone ${ }^{6}$. No entanto, essa derivação é pouco insinuada por Marx e, com a exceção parcial de Adorno, que faz círculos ao redor da questão da mimese e da reificação sem, em minhas leituras dele, clarificá-la teoricamente, representa efetivamente um ponto cego no mapa da teoria crítica. A exceção parcial seria Benjamin, que parece ter pelo menos vislumbrado os contornos dessa dialética em "O narrador". O que Benjamin alega, aqui, do ponto de vista de um tipo de etnografia materialista, como a perda progressiva da capacidade social espontânea de contar histórias no curso da modernização

6. Gostaria de incluir aqui também as contribuições cruciais à teoria crítica contemporânea feitas por um movimento conhecido em círculos teutófonos como "Wertkritik." Ver o trabalho de Robert Kurz, Roswitha Scholz, Ernst Lohoff, Norbert Trenkl, e outros associados às revistas Krisis e Exit! 
capitalista, e que ele atribui a um eclipse da "experiência" intrincado e subespecificado teoricamente, de toda forma aponta, creio eu, para a distinção teórica fundamental neste caso: aquelas sociedades nas quais o forma-valor está ora ausente ora carecendo de qualquer função socialmente mediativa (que abrangeria uma possível forma social póscapitalista) mediam e reproduzem a elas mesmas diretamente no plano de uma autorrepresentação e reconhecimento consciente e social, não importando quão indiretamente mistificada pelas formas este último possa ser. Para usar termos mais familiares, a sociedade pré- ou não-mercantilista não somente narra a si mesma como parte de sua autolegitimação ideológica - algo, afinal de contas, verdadeiro também para a sociedade mercantilizada, qua ideologia. Tais formas de sociedade não podem reproduzir a elas mesmas exceto na medida em que assumem continuamente a forma "narrativa" na consciência dos indivíduos que as compõem ( $v$. LARSEN, 2001). A sociedade mercantilista não obedece a tais leis reprodutivas. (Isso está de acordo com o que também é, qua forma social mais completamente totalizada da modernidade capitalista, a heterogeneidade da inconformidade espaço-temporal ad hoc da sociedade não mercantilista relativamente autointegrada.) Isto é, por necessidade, a sociedade não-reificada, juntamente com suas formas correspondentes de subjetividade social, media a si própria mimeticamente. A sociedade mediada pelo valor não erradica tais formas de autorreprodução mimética ("narrativa", contação de histórias etc.), apesar de discutivelmente tender tortuosamente em direção a seu objetivo. Porém, ela não os bane para esferas marginais, socialmente não-reprodutíveis. Isso, mais que o eclipse da "experiência" e ascensão da "informação" de Benjamin, intuitivamente certos, mas subteorizados, é o que justificaria, então, o declínio na habilidade social de contar histórias. As pessoas sabem espontaneamente como contá-las - de fato, elas não se conhecem socialmente exceto quando as contam - porque os próprios seres sociais das pessoas não têm, sem elas, outra forma viável.

Porém, mesmo que tal tipologia dialética da forma social qua mimese deva nesse momento permanecer um postulado teórico, com ela, a questão com a qual começamos, a do ponto de vista da crítica imanente como crítica "literária", pode agora ser respondida: tal ponto de vista é a contradição entre valor e mimese, ou entre formas reificadas e miméticas da objetividade. A tendência progressiva do valor - de, para usar o termo de Marx, "socialização associal" - em direção à negação da mimese como uma forma de mediação e reprodução social não somente condena o objeto mimético - a "experiência" e o contar de histórias benjamininanos - a uma existência cada vez mais marginalizada. Também, pela mesma 
lógica, confere a tais objetos uma carga social negativa. A mimese não é meramente o meio transparente no qual uma luta ideológica classista é travada. Nem é, como era para Lukács, confinada ao nível de um serespécie sobre cuja base havia de ser erguida uma estética realista capaz de "vislumbrar o socialismo" - mesmo que possa, de fato, haver muito a ser aprendido sobre essa categoria a partir de um estudo crítico da teoria estética de Lukács. A mimese está em si ligada inseparavelmente a uma forma de socialização da qual a abstração-do-valor é a negação direta e determinada. Mas na medida em que o valor, em sua forma completamente histórica e dinâmica enquanto capital, impulsiona, em conformidade com essa dinâmica, em direção a uma crise social terminal, opondo o capital contra suas próprias condições de possibilidade, o objeto mimético não só preserva, negativamente, os delineamentos de uma forma não-reificada de consciência. Torna-se um ponto de vista apesar de não o único - de onde vislumbrar, do lado mais próximo do valor, o contorno aproximado das coisas por vir.

O fato, enquanto isso, de que o objeto "literário" em sua forma essencial de objeto mimético finalmente esquiva-se da teorização positiva e empírica, apresentando às categorias reificantes deste último ora o que aparenta ser uma impenetrabilidade irracional à cognição teórica (o termo benjaminiano para essa impenetrabilidade é "aura"), ora, na melhor das hipóteses, levando-o às antinomias da "falácia da aplicação", perde sua aparência irracional uma vez que a contradição dialética que embasa essa antinomia teórica - a antítese social e histórica do valor e da mimese - é em si teorizada e firmada via uma segunda reflexão. O que agora se tornou, com o declínio do "contar de histórias", a negatividade irredutível da mimese como uma forma social de objetividade constitui o ponto cego necessário da consciência teórica convencional e reificante porque tal forma de objetividade corresponde diretamente, embora negativamente e in potentia, a uma forma de consciência não-reificada, para uma forma mimética de subjetividade externa e oposta ao alcance social da "teoria". Isto é, o objeto que, em sua forma inicial pseudoempírica de apresentação como objeto "literário", evita a teorização positiva corresponde, no nível de sua realidade categórica subjacente como objeto mimético, ao ponto de vista social e histórico do qual as categorias e autocompreensão reificantes da "teoria" devem ser elas mesmas compreendidas e superadas criticamente. A crítica é imanente ao objeto "literário" na medida e até o ponto em que tal objeto, percebendo sua própria essência por conformar sua própria forma de objetividade negativamente mimética, declara sua incompatibilidade com todas as formas reificantes de consciência e "teoria". A teoria crítica do objeto "literário" é a autoconsciência da forma 
mimética da objetividade - da forma do "sujeito/objeto" diretamente e conscientemente social - em sua negatividade.

Isso deixa inexplorada e não resolvida, por certo, a questão da relação precisa e determinada entre a mimese como o que embasa, negativamente, a possibilidade do objeto "literário" e o contexto dado - a singularidade - do objeto "literário" na forma de um "texto" ou obra individual. $\mathrm{O}$ fato de que o ponto de vista crítico do qual empreender sua crítica reside imanentemente dentro da própria obra na medida em que permanece, formalmente, um objeto mimético - o fato de que uma obra como Amada supre, até esse âmbito, o ponto de vista de sua própria crítica - certamente não absolve qualquer obra por sua vez da crítica mais impiedosa. A negatividade social da forma mimética não pode, sob quaisquer circunstâncias, ser atribuída diretamente às próprias obras individuais. A "obra” não é a antimercadoria. Como objeto mimético, sua tarefa é a de enquadrar e fundamentar o fluxo negativo da consciência não-reificada - ou o que seria tal consciência - e nada mais. Ela pode falhar em sua tarefa - pois esse potencial de fracasso, também, é o que a torna uma "obra". Perder de vista esse princípio fundamental (por si só) da crítica imanente e postular uma negatividade diretamente estética, atribuindo um agenciamento [agency] radical ora às próprias obras, ora à arte ou literatura como categorias gerais, é arriscar voltar às antinomias engessadas da "teoria": há uma falácia do "agenciamento" correspondente a cada falácia de "aplicação". Um poema ou um romance não age mais que um sonho ou fantasia - isto é, eles agem somente na medida em que nenhuma ação social consciente é possível exceto quando mediada por tais objetos miméticos.

É a essa relação da forma mimética com a obra individual e o caminho (o método) levando à crítica imanente de uma à outra - e de volta - que espero apresentar mais detalhes em elaborações futuras ao "Princípio de Crítica Imanente”. Ausente uma clareza teórica e metodológica absoluta quanto ao ponto de vista de tal crítica, contudo, esse caminho leva, na melhor das hipóteses, a insights fortuitos dos quais então se torna impossível traçar o caminho de volta. E, na pior delas, pode levar a nenhum lugar que não a paralisia crítica reificada do que é considerada a “teoria” literária e cultural de hoje.

Tradução: Charles Albuquerque Ponte 


\section{2 - Remate de Males 30.1 \\ REFERÊNCIAS BIBLIOGRÁFICAS}

ADORNO, T. The Essay as Form. In Notes to Literature, vol. 1. trans. Shierry Weber Nicholsen. New York: Columbia UP, 1991. p. 3-23.

. Cultural Criticism and Society. In: Prisms. trans. Samuel Weber and Shierry Weber. Cambridge: MIT P, 1983. p. 17-34.

. The Positivist Dispute in German Sociology. trans. Glyn Adey and David Frisby. New York: Harper and Row, 1976. p. 1-86; 105-122.

LARSEN, Neil. Determinations. London: Verso, 2001.

. The Idiom of Crisis: On the historical Immanence of language in Adorno, em RICHTER (ed.), Language without soil: Adorno and late philosophical modernity, Gerhard Richter (ed.) Nova York: Fordham University Press, 2010.

MARX. K. Capital, vol. I. trans. Ben Fowkes. London: Penguin, 1990.

POSTONE, Time, Labor and Social Domination. Cambridge: Cambridge UP, 1996. p. 84120. 